This item was submitted to Loughborough's Research Repository by the author.

Items in Figshare are protected by copyright, with all rights reserved, unless otherwise indicated.

\title{
Using the DIAL-F systems model as the conceptual framework for an audit of in-patient falls resk management
}

PLEASE CITE THE PUBLISHED VERSION

http://dx.doi.org/10.1177/2327857914031018

\section{PUBLISHER}

(C) Human Factors and Ergonomics Society

\section{VERSION}

AM (Accepted Manuscript)

\section{PUBLISHER STATEMENT}

This work is made available according to the conditions of the Creative Commons Attribution-NonCommercialNoDerivatives 4.0 International (CC BY-NC-ND 4.0) licence. Full details of this licence are available at: https://creativecommons.org/licenses/by-nc-nd/4.0/

\section{LICENCE}

CC BY-NC-ND 4.0

\section{REPOSITORY RECORD}

Hignett, Sue, Jane Youde, and James Reid. 2019. "Using the DIAL-F Systems Model as the Conceptual Framework for an Audit of In-patient Falls Resk Management". figshare. https://hdl.handle.net/2134/25390. 
Hignett, S., Youde, J., Reid, J. (2014) Using the DIAL-F systems model as the conceptual framework for an audit of inpatient falls risk management. Proceedings of the HFES 2014 International Symposium on Human Factors and

Ergonomics in Health Care. Chicago, USA. 9-11 March 2014

\title{
Using the DIAL-F Systems Model as the Conceptual Framework for an Audit of In-Patient Falls Risk Management
}

\author{
Sue Hignett ${ }^{1}$, Jane Youde $^{2}$, James Reid ${ }^{3}$ \\ ${ }^{1}$ Loughborough University, UK., \\ ${ }^{2}$ Derby Hospitals NHS Foundation Trust, UK., \\ ${ }^{3}$ University Hospitals of Leicester NHS Trust, UK.
}

\begin{abstract}
Most interventions for managing (reducing) the risks associated with in-patient falls have used a clinical approach to address underlying frailty and illness (physical and mental) with drugs, technology and therapy. This paper reports the results of a two stage audit on in-patient falls risk management at two teaching hospitals in the UK in July 2013 using the DIAL-F systems model as a Human Factors/Ergonomics (HFE) conceptual framework to explore patient engagement with falls risk management. Some safety critical system misalignments were found, and it is suggested that a future HFE intervention might include addressing the problems of (1) reach distances to walking aids and (2) obstacles in the bedside area for patients needing mobility assistance.
\end{abstract}

\section{INTRODUCTION}

The DIAL -F model (Fig. 1) model was developed to address the limitations of other healthcare HFE models (Hignett et al, 2013a). It describes the system elements in terms of transience (duration of action/involvement). The environment (building design, layout, decor, signage, lighting levels etc.) is at the core of the model, as the least frequently changing (most stable) element requiring major investment of financial and human resources for either refurbishment or new building works with accompanying closure of clinical areas. The organisational policies and procedures will probably be modified/updated on an annual basis, but will be a more stable part of the system than technology (equipment, furniture, and medical devices), which may move around the hospital between wards and departments. The staff layer of the model includes clinical, non-clinical (including contractors), and formal and informal (visitors, family) caregivers. Clinical staff will vary, in terms of their permanence, number on duty, knowledge, skills and competencies, between shifts and areas in the organisation. Patients are the most transient element of the system (based on a voluntary agreement/engagement). External factors (society, finance, politics, and professional bodies) impact throughout the system on patient expectations, and staff terms and conditions, as well as on organisational policies.

The separation of the human element of the system (staff and patients) is similar to an HFE model used for risk management of patient handling with four categories (Patient, Carer, Workplace and Organisation) which was implemented as a continuous improvement programme at a large specialist teaching hospital with cost savings in excess of $\$ 5.4$ million over 3 years (Hignett, 2001). 
Hignett, S., Youde, J., Reid, J. (2014) Using the DIAL-F systems model as the conceptual framework for an audit of in-patient falls risk management. Proceedings of the HFES 2014 International Symposium on Human Factors and Ergonomics in Health Care. Chicago, USA. 9-11 March 2014

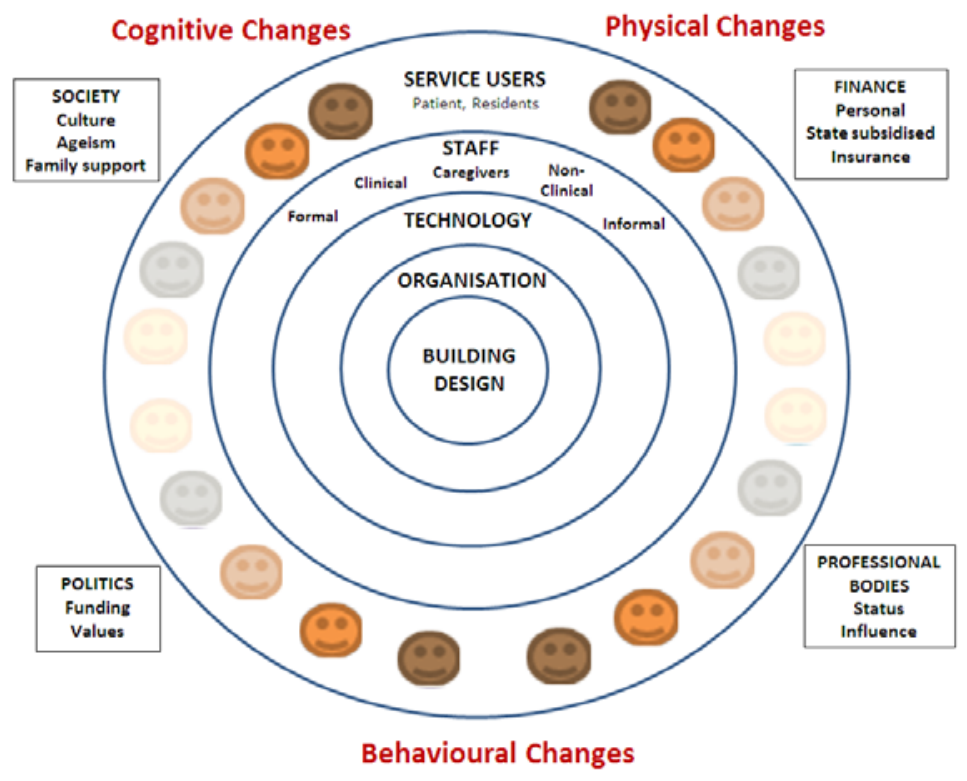

Figure 1. DIAL-F Model (Hignett et al, 2013a; Hignett, 2013)

\section{METHOD}

Wards were selected to be representative of a patient journey in Medicine and included admission/assessment units, general medical wards, cardiology, respiratory, orthogeriatrics, care of the elderly and rehabilitation units (Hignett et al, 2013b). As the NICE (2013) clinical guidelines recommend that all patients aged 65 years and older are considered to be at risk of falling in hospital the data were analysed using age to identify the falls risk rather than the hospital falls risk assessments.

The audit collected data on:

1. Documented assessment data from nursing notes on falls, use of bed rails, mobility, cognitive function, continence and vision.

2. Observable interventions to minimise falls risks in the bed space.

3. Patient engagement in falls risk management.

The data collection was piloted at both hospitals with minor adjustments to improve the definition of 'within reach' and 'obstacles' (to include the bed table). Data were collected on every $2^{\text {nd }}$ bed, excluding patients who were inappropriate for observation (infection control or end of life care).
55 patients were not able or willing to answer questions (absent from bed area, asleep, declined to answer or unwell). The data were analysed descriptively (frequencies) and the risk factors were compared with the whole sample and explored with the Chi-squared and Fisher's exact tests.

\section{RESULTS}

Data were collected from 156 patients. Over 85\% of patients were aged 65 years and older (with 50\% aged 80 years and over); 78\% had mobility problems, $43 \%$ had continence problems (frequency, urgency and nocturia) and $27 \%$ were recorded as having cognitive changes (dementia and delirium). Most patients were in multi-bed bays (87\%) with 51\% sitting in the bedside chair at the time of the audit (40\% in bed and $9 \%$ absent). The datasets from the 2 hospitals were combined for analysis as there were no significant differences for the patient profile with respect to falls risk (age), mobility, cognitive, and continence problems (Fig. 2). 
Hignett, S., Youde, J., Reid, J. (2014) Using the DIAL-F systems model as the conceptual framework for an audit of in-patient falls risk management. Proceedings of the HFES 2014 International Symposium on Human Factors and Ergonomics in Health Care. Chicago, USA. 9-11 March 2014

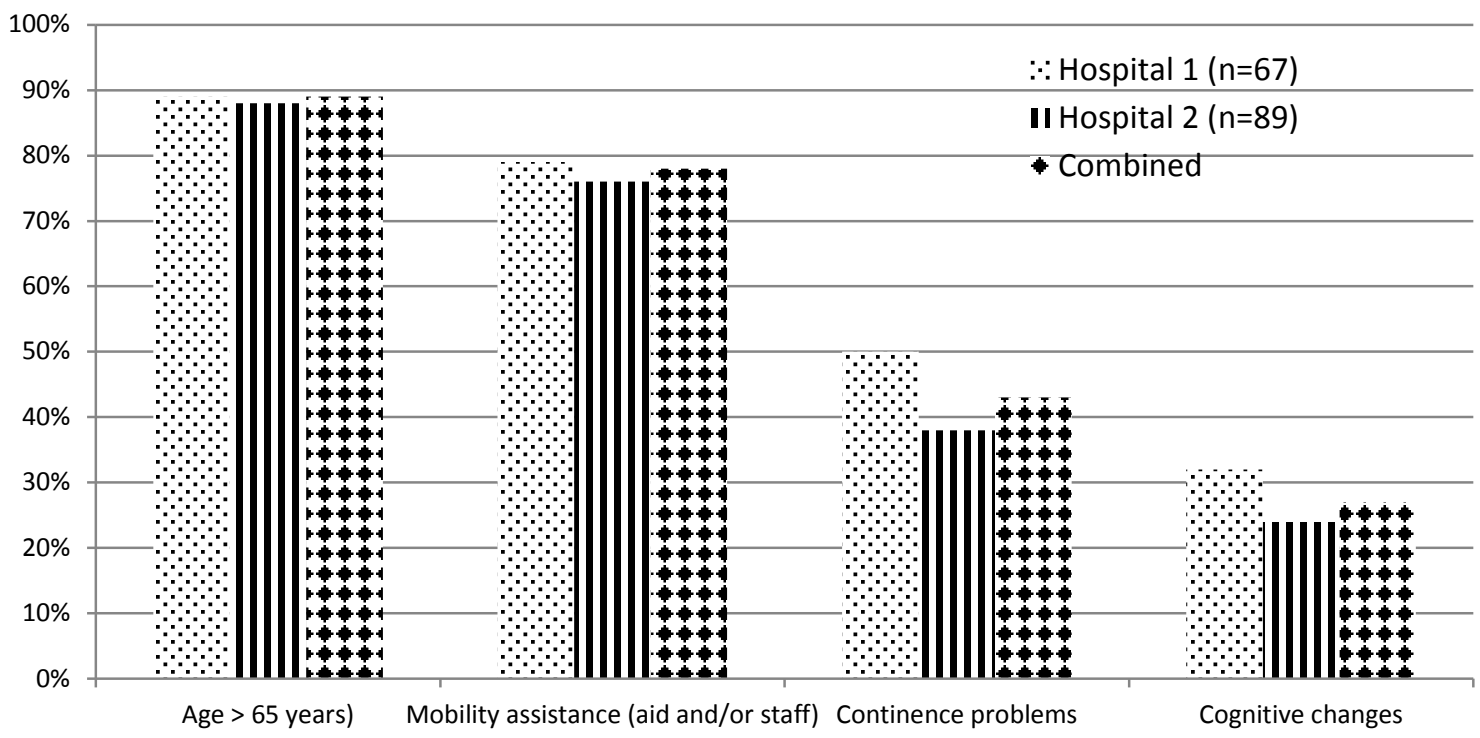

Figure 2. Patient profile from 2 hospitals (no significant differences)

Patients with a falls risk (aged 65 years and over) were significantly more likely than expected to have mobility problems $(\mathrm{P}<0.001)$, continence problems $(\mathrm{P}<0.005)$ and be identified as at risk for pressure ulcers $(\mathrm{P}<0.001)$ but they were not significantly more likely than expected to have cognitive changes. The subset of patients with mobility problems were more likely than expected to have continence problems $(\mathrm{P}<0.001)$ and cognitive problems $(\mathrm{P}<0.005)$. This is a different result to the analysis of reported falls incidents (Hignett et al, 2013b) where two separate cohorts of frail and confused patients were identified. It may reflect an increased focus on dementia assessment since 2008 with improved recording of cognitive changes. However the percentage of patients with cognitive changes (27\%) is lower than reported elsewhere (36\%; Sampson et al, 2009) so this may be a limitation of the small dataset.

The bedside observational data indicated that most of the items usually found on the bedside table (drink, spectacles) were within reach (Fig. 3) but that the call light (on a cord from the wall) might have fallen out of reach (59\% within reach). Only $21 \%$ of walking aids (frames, crutches and sticks) were within reach, with the bedside table often obstructing the bedside area (only $24 \%$ of bedside areas had no obstacles/hazards). $39 \%$ of patients could see signage for the toilet from their bedhead. Bedrails were in the correct configuration (as the bedrail assessment) for $86 \%$ of patients.

$61 \%$ of patients were willing and able to answer questions; as the sampling strategy was not based on falls risk, patients agreeing to respond were not more or less likely than expected to be at risk of a fall. A very high percentage (86\%) of patients knew the location of their nearest toilet but significantly more patients with cognitive changes than expected did not know the location of toilet $(\mathrm{P}<0.001)$. When asked what they would do when they wanted to go the toilet, $51 \%$ said they would 'go alone'. Of these, significantly more than expected of patients needing mobility assistance stated that they would go to the toilet alone $(\mathrm{P}<0.001)$. 
Hignett, S., Youde, J., Reid, J. (2014) Using the DIAL-F systems model as the conceptual framework for an audit of in-patient falls risk management. Proceedings of the HFES 2014 International Symposium on Human Factors and Ergonomics in Health Care. Chicago, USA. 9-11 March 2014

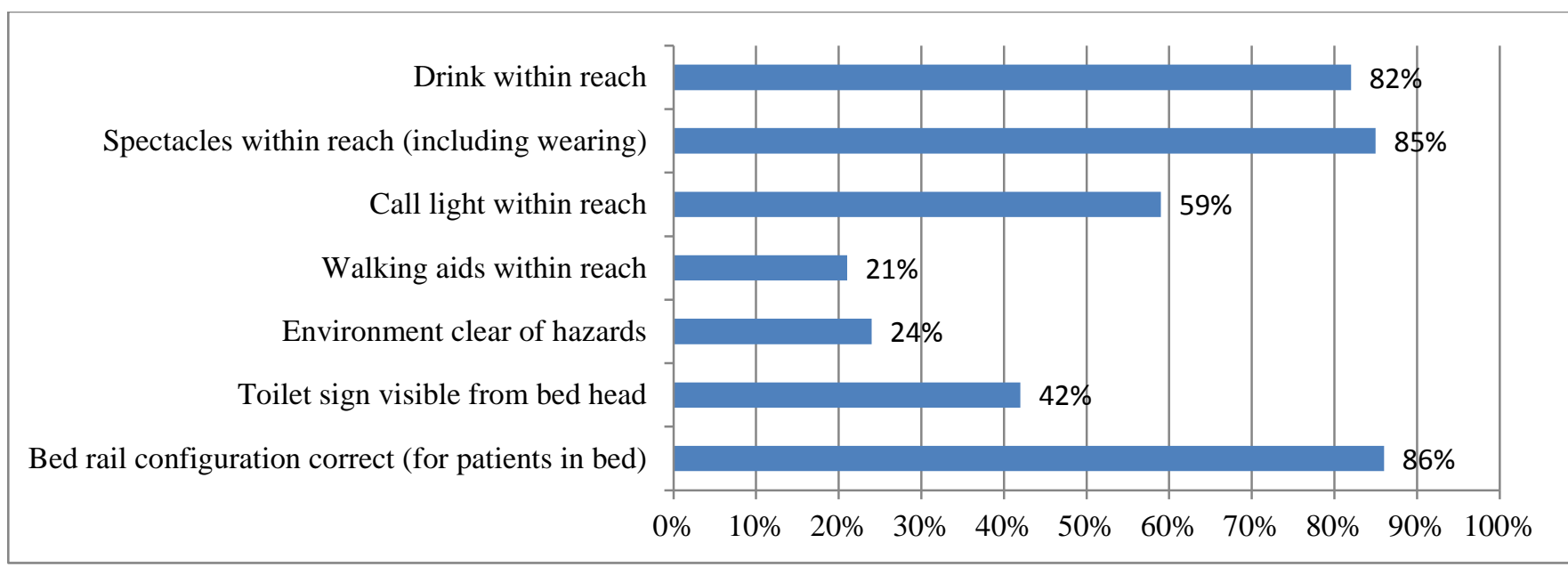

Figure 3. Observational data for falls interventions and hazards

\section{DISCUSSION}

The limitations of this audit are mostly associated with the small dataset of 156 patients. However when considered with previous data from the National Learning and Reporting System (NRLS; Hignett et al, 2013b) and an audit of bedrail use (Hignett et al, 2013c) it is suggested that there may be some HFE trends emerging relating to design of the environment for patients needing mobility assistance (frail) and cognitive changes (confused).

An analysis of national incident report (Hignett et al, 2013c) found that patients were significantly more likely than expected to be harmed if they fell when wandering/mobilising and going to/from the toilet (especially frail patients). The confused patients were significantly less likely than expected to be found following a fall in the toilet. The results can be interpreted within the current audit for frail patients with more continence problems than expected (and therefore more likely to want to go to the toilet) and for confused patients as being less likely than expected to know the location of the nearest toilet and possibly having fewer falls in the toilet as they did not find it.

In an HFE approach, using DIAL-F as the conceptual framework, the patient is described as an active participant in the falls risk management system. From the audit it was found that 39 patients (51\%) would go to the toilet alone, but only $24 \%$ of the whole sample had walking aids with reach. Tuunainen et al (2013) found that the most common reason for falling by habitual fallers was poor balance linked to rising from a chair and not using an assistive device (possibly because they could not reach it). For first time fallers the most common reasons for falling were vertigo and dizziness (35\%), followed by a trip or missed step (28\%), again of concern as only $24 \%$ of bedside areas were free from obstacles and hazards. Oliver (2008) also suggested that there might be 2 distinct populations of fallers, 'one falling early during a period of transient confusion, postural instability or hypotension as they recover from acute illness; the other with postural instability, combined with restlessness, wandering or risk behaviour, falling repeatedly'.

This suggests that an HFE intervention for the two populations might include:

(1) addressing the problem of reach distances to walking aids and obstacles in the bedside area for patients needing mobility assistance.

(2) better signage to assist confused patients locate the toilet.

These will be considered for a future intervention package to include the patient as an active member of the risk management system. 
Hignett, S., Youde, J., Reid, J. (2014) Using the DIAL-F systems model as the conceptual framework for an audit of in-patient falls risk management. Proceedings of the HFES 2014 International Symposium on Human Factors and Ergonomics in Health Care. Chicago, USA. 9-11 March 2014

\section{REFERENCES}

Bowers, B., Lloyd, J., Lee, W., Powell-Cope, G., Baptiste, A. (2009). Biomechanical Evaluation of Injury Severity Associated with Patient Falls from Bed. Rehabilitation Nursing, 33, 6, 253-259.

Hignett, S. (2013) Why Design Starts with People. The Health Foundation: Patient Safety Resource Centre. http://patientsafety.health.org.uk/sites/default/files/r esources/why_design_starts_with_people.pdf (Accessed 10 June 2013)

Hignett, S., Griffiths, P., Sands G., Wolf, L., Costantinou, E. (2013a) Patient Falls: Focusing on Human Factors rather than Clinical Conditions. Proceedings of the HFES 2013 International Symposium on Human Factors and Ergonomics in Health Care. Baltimore, USA. 11-13 March 2013.

Hignett, S., Goodwin, E., O’Hagan, B., Youde, J. (2013b) Audit of falls interventions using a Human Factors/ Ergonomics (HFE) approach. Proceedings of British Geriatrics Society 14th International Falls \& Postural Stability Conference Sept. Bristol, UK.

Hignett, S., Sands, G., Griffiths, P. (2013c) InPatient Falls: What can we learn from incident reports? Age \& Ageing. 42, 527-531.

Hignett, S. (2010) Technology and Building Design initiatives in interventions to reduce the incidence and injuries of Elderly In-Patient Falls Healthcare Environments Research and Design Journal 3, 4, 62-84.

Hignett S. (2001). Embedding ergonomics in hospital culture: top-down and bottom-up strategies. Applied Ergonomics. 32, 61-69.

Ko, A., Van Nguyen, H., Chan, L., Shan, Q., Ding, X.M., Leonard, D., Chan, D.K.Y., Brock, K., Clemson, L. (2012). Developing a self-reported tool on fall risk based on toileting responses on inhospital falls. Geriatric Nursing, 33, 1, 9-16.

National Patient Safety Agency 2010 Slips trips and falls data update. NPSA, London. www.nrls.npsa.nhs.uk (Accessed 27th January 2014)
Royal College of Physicians. 2012. Report of the 2011 inpatient falls pilot audit. London: RCP.

Oliver, D. (2008). Preventing falls and falls injuries in hospitals and long term care facilities. Reviews in Clinical Gerontology, 17, 75-91.

Sampson, E.L., Blanchard, M.R., Jones, L., Tookman, A., King, M. (2009). Dementia in the acute hospital: prospective cohort study of prevalence and mortality. British Journal of Psychiatry, 195, 61-6.

Tuunainen, E., Jäntti, P., Pyykko, I., MoisioVilnenius, P., Toppila, E. (2013). Intervention to prevent falls in elderly adults living in a residential home. Journal of the American Geriatrics Society. $61,8,1426-1427$. 